\title{
Embolia pulmonar séptica secundária à tromboflebite jugular: um caso de síndrome de Lemierre*
}

\author{
Septic pulmonary embolism secondary to jugular \\ thrombophlebitis: a case of Lemierre's syndrome
}

\author{
Denise Rossato Silva ${ }^{1}$, Marcelo Basso Gazzana ${ }^{2}$, Ricardo Albaneze', \\ Paulo de Tarso Roth Dalcin ${ }^{3}$, Josi Vidart ${ }^{4}$, Nei Gulcó ${ }^{3}$
}

\begin{abstract}
Resumo
A síndrome de Lemierre é caracterizada pela infecção aguda da orofaringe, complicada por trombose venosa jugular interna secundária à tromboflebite séptica, e por infecções metastáticas a vários órgãos distantes-mais freqüentemente os pulmões. Relatamos um caso de síndrome de Lemierre em uma mulher de 56 anos que se apresentou com massa cervical à direita e febre. Trombose venosa jugular interna foi demonstrada na ecografia. A tomografia computadorizada de tórax revelou múltiplas opacidades em ambos os pulmões. Uma biópsia pulmonar cirúrgica foi realizada por suspeita de metástases pulmonares. 0 exame anatomopatológico revelou êmbolos sépticos em parênquima pulmonar. Retrospectivamente, a paciente relatou história de faringite duas semanas antes da hospitalização. Após o diagnóstico, foi tratada com antibióticos de amplo espectro (cefuroxima por 7 dias e azitromicina por 5 dias e, posteriormente, devido à persistência de febre, cefepime por 7 dias). A tomografia computadorizada de tórax, realizada um mês após, mostrou resolução das opacidades.
\end{abstract}

Descritores: Embolia pulmonar; Abscesso pulmonar; Tromboflebite; Veias jugulares; Faringite.

\begin{abstract}
Lemierre's syndrome is characterized by acute oropharyngeal infection, complicated by internal jugular venous thrombosis secondary to septic thrombophlebitis, and by metastatic infections in various distant organs-most commonly in the lungs. We report a case of Lemierre's syndrome in a 56-year-old female who presented with right-sided neck mass and fever. Right internal jugular venous thrombosis was demonstrated on an ultrasound. A computed tomography scan of the chest revealed multiple opacities throughout both lungs. An open surgical biopsy was performed due to suspicion of pulmonary metastases. Anatomopathological examination revealed septic emboli in lung parenchyma. Retrospectively, the patient reported a history of pharyngitis two weeks prior to hospitalization. After the diagnosis had been made, the patient was treated with broad-spectrum antibiotics (cefuroxime for 7 days and azithromycin for 5 days; subsequently, because fever persisted, cefepime for 7 days). One month later, a computed tomography scan of the chest revealed resolution of the opacities.
\end{abstract}

Keywords: Pulmonary embolism; Lung abscess; Thrombophlebitis; Jugular veins; Pharyngitis.

\section{Introdução}

A síndrome de Lemierre (necrobacilose ou sepse pósangina) é causada por uma infecção aguda da orofaringe com tromboflebite séptica secundária da veia jugular interna (VJI), freqüentemente complicada por infecções metastáticas. É uma doença grave causada pela bactéria anaeróbia Fusobacterium necrophorum. Tipicamente ocorre em adolescentes e adultos jovens saudáveis. A infecção origina-se nas tonsilas palatinas e tecidos circunjacentes na maioria dos casos, mas também pode iniciar-se como faringite, parotidite, otite média, sinusite, infecção odontogênica e mastoidite. Posteriormente, ocorre a infecção do espaço faríngeo lateral, que contém a $\mathrm{VJl}$, levando à tromboflebite séptica deste vaso. A bacteremia é complicada por êmbolos sépticos para diversos locais, como os pulmões (mais freqüente), articulações e ossos. Na era pré-antibiótico, esta síndrome não era incomum e tinha evolução fulminante,

* Trabalho realizado no Hospital de Clínicas de Porto Alegre, Universidade Federal do Rio Grande do Sul - UFRGS - Porto Alegre (RS) Brasil.

1. Médico Pneumologista. Hospital de Clínicas de Porto Alegre, Universidade Federal do Rio Grande do Sul - UFRGS - Porto Alegre (RS) Brasil.

2. Médico Assistente. Serviço de Pneumologia, Hospital de Clínicas de Porto Alegre, Universidade Federal do Rio Grande do Sul - UFRGS - Porto Alegre (RS) Brasil.

3. Professor Associado. Departamento de Medicina Interna, Faculdade de Medicina, Universidade Federal do Rio Grande do Sul - UFRGS - Porto Alegre (RS) Brasil.

4. Médica Residente em Medicina Interna. Hospital de Clínicas de Porto Alegre, Universidade Federal do Rio Grande do Sul - UFRGS - Porto Alegre (RS) Brasil.

Endereço para correspondência: Marcelo Basso Gazzana. Serviço de Pneumologia, Hospital de Clínicas de Porto Alegre, Rua Ramiro Barcelos, 2350, $2^{\circ}$ andar, Sala 2050, CEP 90035-003, Porto Alegre, RS, Brasil.

Tel 5551 2101-8241. E-mail: marcgaz@terra.com.br

Apoio financeiro: Nenhum.

Recebido para publicação em 5/3/2008. Aprovado, após revisão, em 17/4/2008. 
geralmente fatal, entre 7 e 15 dias. Embora rara nos dias atuais, há evidências do ressurgimento dessa condição nos últimos anos, com alguns relatos de casos na literatura. Isto possivelmente está associado à limitação do uso de antimicrobianos para o tratamento de infecções das vias aéreas superiores a fim de evitar sua utilização desnecessária em casos de etiologia viral. Não há descrição de casos semelhantes em nosso meio. ${ }^{(1-4)}$

\section{Relato de caso}

Mulher de 56 anos, branca, procurou o serviço de emergência devido à tumoração em região cervical à direita, dolorosa, há 5 dias. Apresentava tosse seca e febre alta há 3 dias. Negava tabagismo. Era hipertensa e diabética e havia tido um infarto do miocárdio há 3 anos. Na admissão, a paciente apresentava-se desidratada, afebril (temperatura axilar, $36,7^{\circ} \mathrm{C}$ ), eupnéica, com tumoração cervical dolorosa à direita. Os exames laboratoriais revelaram velocidade de hemossedi- mentação aumentada (92 mm). A ecografia cervical mostrou trombose em VJl direita, sendo iniciada anticoagulação no quarto dia de internação. A radiografia de tórax demonstrou pelo menos dois nódulos no pulmão esquerdo, um aparentemente escavado e outro com $18 \mathrm{~mm}$ de diâmetro na base, além de lesão irregular com $25 \mathrm{~mm}$ de diâmetro no lobo superior direito. Foi realizado ecocardiograma transesofágico para descartar a hipótese de endocardite, o qual não demonstrou presença de vegetações. Devido à hipótese de pneumonia, foi iniciado tratamento empírico com $500 \mathrm{mg}$ de cefuroxima, via oral, a cada $12 \mathrm{~h}$. A tomografia de tórax revelou múltiplas opacidades bilaterais, de aspecto sugestivo de implante metastático (Figura 1). Prosseguindo a investigação, a paciente foi submetida à broncoscopia flexível, cujos achados endoscópicos foram normais. A análise microbiológica do lavado broncoalveolar para pesquisa de bacilo álcool-ácido resistente e fungos, assim como seu estudo citopatológico e culturas, foram negativos. Com a hipótese de neoplasia metas-
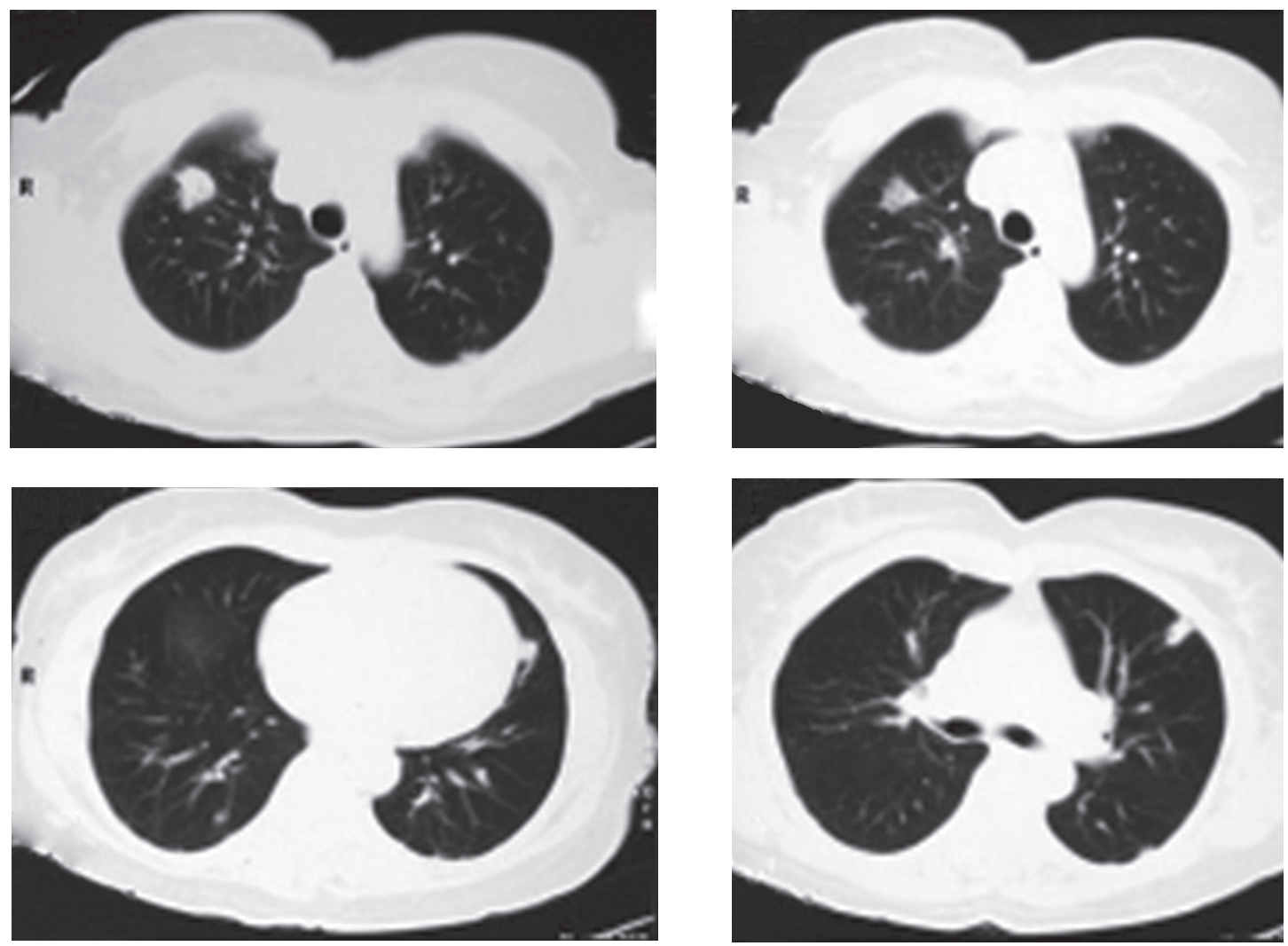

Figura 1 - Cortes de tomografia computadorizada do tórax sem injeção de contraste mostrando múltiplas opacidades pulmonares bilaterais. 

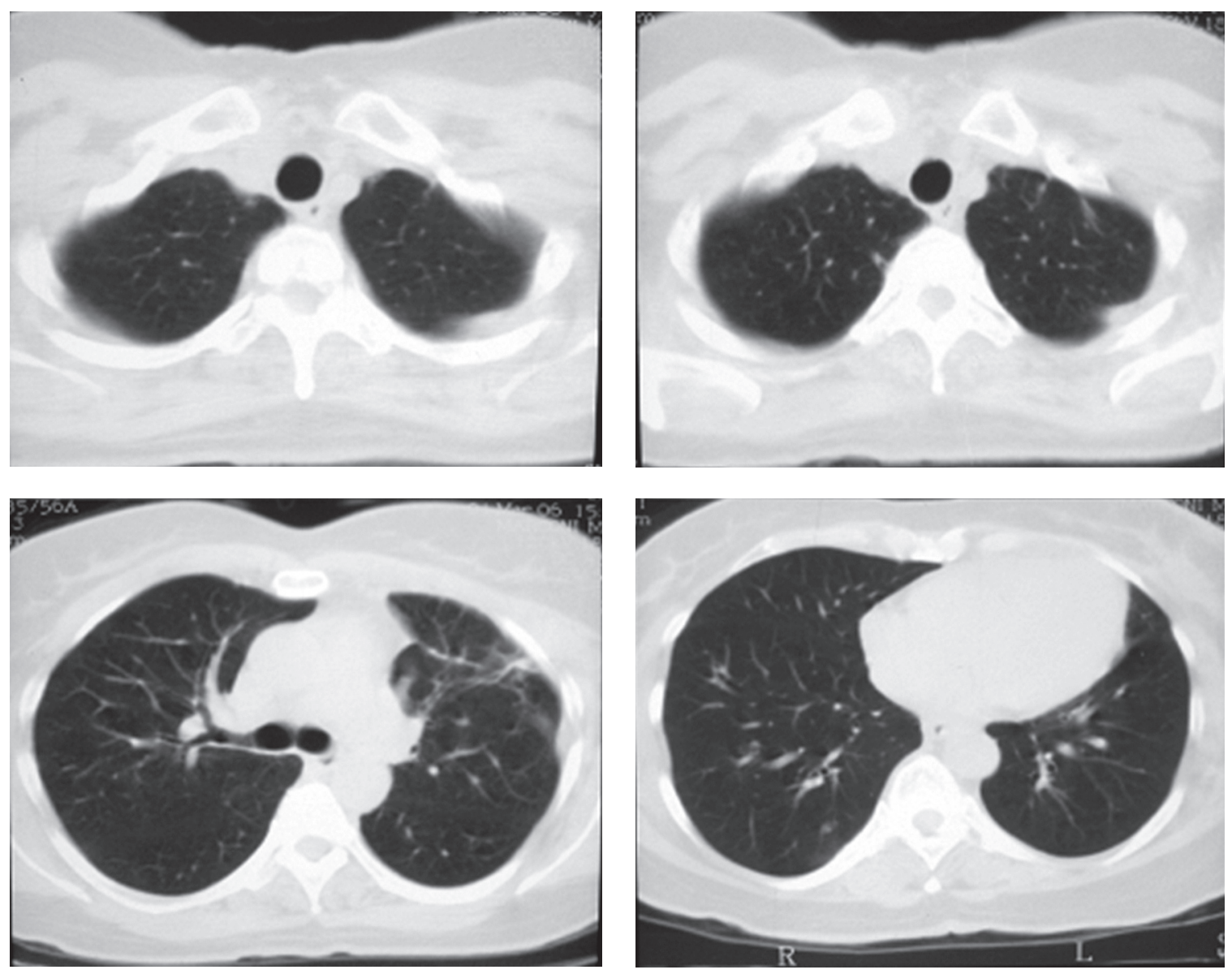

Figura 2 - Cortes de tomografia computadorizada do tórax sem injeção de contraste mostrando regressão praticamente total das opacidades pulmonares após tratamento com antibióticos.

tática, a paciente foi submetida à biópsia pulmonar cirúrgica, cujo exame anatomopatológico mostrou inflamação supurativa crônica abscedada em organização em parênquima pulmonar. Frente à hipótese de síndrome de Lemierre devido à trombose jugular associada à embolia séptica pulmonar, a paciente foi questionada sobre a ocorrência de amigdalite no início do quadro. A paciente não recordava, mas a filha lembrou que a mesma havia usado $500 \mathrm{mg}$ de amoxicilina, via oral, a cada $8 \mathrm{~h}$ por 10 dias, para tratamento de amigdalite alguns dias antes da internação. Na admissão hospitalar, a paciente recebeu um curso de cefuroxima (750 mg endovenoso a cada 8 horas por 7 dias) concomitante a azitromicina

\section{Quadro 1 - Características da Síndrome de Lemierre.}

- História de infecção aguda da orofaringe cerca de uma semana antes da apresentação

- Febre alta, calafrios

- Dor e edema em região cervical

- Trombose da veia jugular interna

- Envolvimento pulmonar (múltiplos nódulos/opacidades como ou sem cavitação, infiltrados, derrame pleural, abscessos)

- Infecções metastáticas para outros sítios (articulações, ossos, fígado, rim, baço, pele, tecidos moles e meninges)

- Diagnóstico: hemoculturas anaeróbias ou culturas obtidas dos sítios de infecção metastática

- Resposta lenta aos antibióticos 
(500 mg via oral por 5 dias),que, por persistência da febre, foi modificado para cefepime $(1.000 \mathrm{mg}$ a cada 12 horas por 7 dias). A tomografia computadorizada de tórax de controle após este curso de antibióticos mostrou regressão praticamente total das opacidades (Figura 2). Permaneceu afebril desde o terceiro dia do novo curso de antibióticos. Nenhum microrganismo foi isolado das hemoculturas e culturas do lavado broncoalveolar. A anticoagulação foi suspensa após 20 dias de uso, pela falta de evidência de benefício na síndrome de Lemierre.

\section{Discussão}

A sindrome de Lemierre parece ter sido relativamente comum na era pré-antibiótico. Embora permaneça uma doença rara (incidência de 1 caso/1.000.000 pessoas/ano), houve um aumento no número de casos relatados desde 1990. Uma hipótese para o ressurgimento da doença é a menor prescrição de antibióticos para amigdalites. 0 aumento dos casos de bacteremia por esta bactéria também pode ser devido à melhora nas técnicas de hemocultura anaeróbia. ${ }^{(1)}$

As fusobactérias são bacilos Gram negativos anaeróbios obrigatórios que fazem parte da flora normal do trato respiratório superior, genital feminino e gastrointestinal. Devido aos abscessos necróticos produzidos pelo Fusobacterium necrophorum, a condição passou a ser conhecida como necrobacilose. 0 primeiro caso foi descrito em 1900 por Courmont e Cade. Foi melhor caracterizada, em 1936, por André Lemierre, em um discurso sobre septicemias anaeróbias, em que dividiu os pacientes em seis grupos de acordo com a origem da infecção: lesões inflamatórias da nasofaringe (abscesso amigdaliano/periamigdaliano), lesões da boca e mandíbula, otite média ou mastoidite, endometrite pós-parto purulenta, apendicite e infecções do trato urinário. 0 primeiro grupo foi descrito como "septicemias anaeróbias pós-angina"; estes pacientes eram jovens, previamente sadios, com faringoamigdalite ou abscesso periamigdaliano, freqüentemente seguido de edema e aumento da sensibilidade do músculo esternocleidomastoideo devido à tromboflebite séptica da VJl. Febre alta e calafrios desenvolviam-se dentro de uma semana e, subseqüentemente, abscessos metastáticos para o pulmão, ossos, articulações, pele e tecidos moles ${ }^{(1)}$ (Quadro 1). Nossa paciente encontra-se fora da faixa etária classicamente envolvida nesta síndrome e não era previamente hígida (apresentava hipertensão arterial e diabete melito). Entretanto, existem alguns relatos na literatura de pacientes com esta síndrome com idade mais avançada e com co-morbidades. ${ }^{(1,5,6)}$

A origem da infecção pode não ser a garganta, mas sim o ouvido, mastóide ou até mesmo infecção dentária. Ao mesmo tempo, alguns autores não requerem o isolamento de Fusobacterium sp. para o diagnóstico. ${ }^{(1)}$

Considerando que o Fusobacterium sp. faz parte da flora normal, deve haver algum fator que precipite a infecção invasiva, como o dano da mucosa por faringite viral ou bacteriana. A infecção recente pelo vírus Epstein-Barr pode induzir imunossupressão, facilitando a infecção bacteriana secundária. ${ }^{(1)}$ Foi relatado na literatura um paciente com síndrome de Lemierre com variações em genes da coagulação associadas com eventos trombóticos, sugerindo uma predisposição genética para o desenvolvimento desta síndrome. ${ }^{(7)}$ Casos associados com coagulopatia e deficiência do fator XII também já foram descritos. ${ }^{(8,9)}$

0 Fusobacterium sp. é difícil de ser identificado e se confunde com Bacteroides sp. Freqüentemente é encontrado associado com outros patógenos (33\% dos casos). Outros organismos ocasionalmente encontrados são o Streptococcus sp., Bacteroides sp., Peptostreptococcus sp. e Eikenella corrodens ${ }^{(1,2)}$. Klebsiella pneumoniae foi descrita em um paciente diabético. ${ }^{(8)} \mathrm{Na}$ paciente do caso relatado, não foi identificado nenhum microrganismo. 1sto pode dever-se ao uso prévio de antibióticos, bem como a não solicitação de hemoculturas anaeróbias, uma vez que a síndrome de Lemierre não foi considerada entre as hipóteses diagnósticas iniciais.

0 início da doença ocorre com febre de $39-41^{\circ} \mathrm{C}$ e calafrios, 4 a 5 (até 12) dias após o início da faringite. Dor e rigidez no pescoço podem ocorrer. Linfadenopatia cervical pode estar presente (uni- ou bilateral), normalmente no triângulo anterior. Edema e dor no ângulo da mandíbula ou anterior e paralelo ao músculo esternocleidomastoideo refletem o desenvolvimento de tromboflebite da VJI $(26 \%$ a $45 \%$ dos casos). A paciente deste caso iniciou com sintomas 5 dias após o início da faringite. ${ }^{(1)}$

0 envolvimento pulmonar nesta síndrome é extremamente comum (até 97\% dos casos). As lesões pulmonares podem se manifestar já no primeiro dia 
de sepse. Podem ocorrer dor pleurítica intensa com dispnéia e, freqüentemente, hemoptise. Estertores crepitantes localizados e atrito pleural podem ser auscultados. A radiografia de tórax mostra tipicamente múltiplas opacidades bilaterais e pequenos derrames pleurais. É possível detectar-se cavitação já na primeira radiografia. Pode haver rápida progressão das lesões, mesmo na vigência de antibióticos. Empiema desenvolve-se entre 10\% a 15\% dos casos. Abscesso, pneumotórax e pneumatoceles são descritos. Com administração de contraste, ocorre realce periférico das lesões com áreas centrais de redução da atenuação. 0 diagnóstico diferencial é com pneumonia (bacteriana aguda, atípica, aspirativa e estafilocócica)..$^{(1,2,11-14)}$

Os pacientes apresentam leucocitose com neutrofilia. As provas de função hepática estão alteradas em 50\% dos casos. 0 Fusobacterium sp. leva no mínimo $48 \mathrm{~h}$ e às vezes até 7 dias para crescer em hemoculturas, sendo identificado também por biologia molecular. ${ }^{(1)}$ A tromboflebite da VJl é confirmada através de ecografia ou tomografia..$^{(1,12)}$

A resposta aos antibióticos é lenta. 0 tempo médio entre o início do tratamento e a resolução da febre varia de 8 a 12 dias. 0 Fusobacterium sp. geralmente é sensível à penicilina, clindamicina, metronidazol, cefalosporinas, tetraciclina e cloranfenicol. 0 esquema inicial sugerido é penicilina e metronidazol por pelo menos quatro semanas. Nos casos de falha com penicilina, opções são a ticarcilina/clavulanato e o imipenem..$^{(1,13)}$ No caso relatado, foram usados amoxicilina, cefuroxima, cefepime e azitromicina. A paciente ficou afebril somente após o terceiro esquema de antibiótico, talvez não por falha dos antibióticos, mas pelo reduzido tempo de uso dos mesmos.

0 uso de anticoagulantes é controverso. É reservado para pacientes com progressão retrógrada ao seio cavernoso. A ligação da VJl somente está indicada nos casos com embolização séptica persistente apesar dos antibióticos. ${ }^{(1)}$

$\mathrm{Na}$ era pré-antibiótico, o prognóstico desta síndrome era ruim. Com o tratamento antibiótico, apesar da gravidade da sepse, a recuperação plena é o habitual, com taxas de mortalidade variando de $0 \%$ a $18 \%$ nas séries. ${ }^{(1)}$

A presença de opacidades pulmonares em paciente com febre e trombose venosa jugular concomitante deve lembrar a possibilidade de síndrome de Lemierre.

\section{Referências}

1. Riordan T, Wilson M. Lemierre's syndrome: more than a historical curiosa. Postgrad Med J. 2004;80(944):328-34.

2. Golpe R, Marín B, Alonso M. Lemierre's syndrome (necrobacillosis). Postgrad Med J. 1999;75(881):141-4.

3. Bliss SJ, Flanders SA, Saint S. Clinical problem-solving. A pain in the neck. N Engl J Med. 2004;350(10):1037-42.

4. Riordan T. Human infection with Fusobacterium necrophorum (Necrobacillosis), with a focus on Lemierre's syndrome. Clin Microbiol Rev. 2007;20(4):622-59.

5. Shibasaki Warabi Y, Yoshikawa H, ldezuka J, Yamazaki M, Onishi Y. Cerebral infarctions and brain abscess due to Lemierre syndrome. Intern Med. 2005;44(6):653-6.

6. Morizono S, Enjoji M, Sonoda N, Fukushima M, Kuniyoshi M, Kotoh K,et al. Lemierre's syndrome: Porphyromonas asaccharolytica as a putative pathogen. Intern Med. 2005;44(4):350-3.

7. Singaporewalla RM, Clarke MJ, Krishnan PU, Tan DE. Is this a variant of Lemierre's syndrome? Singapore Med J. 2006;47(12):1092-5.

8. Constantin JM, Mira JP, Guerin R, Cayot-Constantin S, Lesens 0 , Gourdon F, et al. Lemierre's syndrome and genetic polymorphisms: a case report. BMC Infect Dis. 2006;6:115.

9. Georgopoulos S, Korres S, Riga M, Balatsouras D, Kotsis G, Ferekidis E. Lemierre's syndrome associated with consumption coagulopathy and acute renal failure: a case report. J Laryngol Otol. 2008;122(5):527-30.

10. Hlibczuk V. Lemierre's syndrome complicating bacterial pharyngitis in a patient with undiagnosed factor XII deficiency [abstract]. J Emerg Med. 2007;32(4):365-9.

11. Screaton NJ, Ravenel JG, Lehner PJ, Heitzman ER, Flower CD. Lemierre syndrome: forgotten but not extinct--report of four cases. Radiology. 1999;213(2):369-74.

12. Cook RJ, Ashton RW, Aughenbaugh GL, Ryu JH. Septic pulmonary embolism: presenting features and clinical course of 14 patients. Chest. 2005;128(1):162-6.

13. Nguyen-Dinh KV, Marsot-Dupuch K, Portier F, Lamblin $B$, Lasjaunias P. Lemierre syndrome: usefulness of $\mathrm{CT}$ in detection of extensive occult thrombophlebitis. J Neuroradiol. 2002;29(2):132-5.

14. UpToDate [homepage on the Internet]. Massachusetts: UpToDate, Inc. c2008. [updated 2007 Jan 3; cited 2008 Feb 28]. Available from: http://www.uptodateonline.com 